\title{
PEMETAAN DIGITAL BERBASIS SISTEM INFORMASI \\ GEOGRAFIS DALAM ANALISIS KERUANGAN SERTIFIKASI GURU SEKOLAH DASAR
}

\author{
Dhi Bramasta \\ Program Studi Pendidikan Guru Sekolah Dasar \\ Universitas Muhammadiyah Purwokerto \\ Email:dhi_bramasta@yahoo.co.id
}

\begin{abstract}
Abstrak. Pendidikan secara umum merupakan segala upaya yang direncanakan untuk mempengaruhi orang lain baik individu, kelompok, atau masyarakat sehingga individu, kelompok, atau masyarakat melakukan apa yang diharapkan oleh pelaku pendidikan. Dalam hal ini dengan pendidikan diharapkan peserta didik bisa secara aktif mengembangkan potensi dirinya.

Dalam menunjang pendidikan yang berkualitas tentunnya didukung dengan meratanya distribusi sekolah dan guru yang kompeten serta profesional dalam bidangnya di sekolah. Persebaran atau distribusi sekolah yang tidak merata secara geografis, berpengaruh terhadap kualitas pendidikan penduduk dalam suatu wilayah. Dalam lingkup sekolah jumlah guru memegang peranan dalam mempengaruhi kualitas pembelajaran, sehingga perbandingan jumlah guru bersertifikasi dan yang belum bersertifikasi dalam suatu sekolah akan sangat mempengaruhi kualitas pembelajaran di sekolah. Karena sertifikasi guru merupakan proses uji kompetensi bagi calon guru atau guru yang ingin memperoleh pengakuan dan atau meningkatkan kompetensi sesuai profesi yang dipilihnya. Sertifikasi guru merupakan upaya pemerintah dalam meningkatkan mutu guru yang dikuti dengan peningkatan kesejahteraan guru. Guru yang telah mendapatkan sertifikasi dinyatakan sebagai pendidik yang kompeten dan profesional.

Salah satu cara untuk mengetahui dan menganalisis distribusi sekolah dalam hal ini adalah Sekolah Dasar dengan jalan pemetaan digital berbasis SIG. Peta merupakan data yang sangat penting dalam memberikan informasi yang dibutuhkan oleh berbagai pihak. Data informasi spasial peta berbasis SIG memiliki peran yang sangat penting berbagai bidang. Dalam bidang sosial dan budaya, dalam mengetahui luas dan persebaran lahan pertanian serta kemungkinan pola drainasenya, pendataan dan pengembangan pusat-pusat pertumbuhan dan pembangunan pada suatu kawasan, pendataan dan pengembangan pemukiman penduduk, sekolah, rumah sakit, perkantoran.
\end{abstract}

Kata Kunci : Pemetaan Digital Berbasis SIG, Analisis Keruangan Sertifikasi Guru Sekolah Dasar

\section{LATAR BELAKANG}

Soekidjo Notoatmodjo (2003: 16), menyatakan bahwa pendidikan secara umum adalah segala upaya yang direncanakan untuk mempengaruhi orang lain baik individu, kelompok, atau masyarakat sehingga mereka melakukan apa yang diharapkan oleh pelaku pendidikan. Dalam hal ini dengan pendidikan diharapkan peserta didik bisa secara aktif mengembangkan potensi dirinya.

Agar pembangunan pendidikan dapat berkontribusi terhadap peningkatan kualitas sumber daya manusia, terdapat tiga syarat utama yang harus diperhatikan yaitu : (1) sarana gedung, (2) buku yang memadai dan berkualitas serta (3) guru 
dan tenaga kependidikan yang profesional (Mulyasa, $2005: 3$ ).

Sebagian besar masyarakat modern memandang lembaga-lembaga pendidikan sebagai peranan kunci dalam mencapai tujuan sosial. Pemerintah bersama orang tua telah menyediakan anggaran pendidikan yang diperlukan secara intensif untuk kemajuan sosial dan pembangunan bangsa, untuk mempertahankan nilai-nilai tradisional yang berupa nilai-nilai luhur yang terkandung dalam pembukaan UUD 1945 alinea ke-4 yaitu mencerdaskan kehidupan bangsa. Sehingga menuntut adanya tenaga pendidik yang kompeten dan profesional, maka guru harus memiliki kualitas sumber daya manusia yang lebih baik yang disesuaikan dengan perkembangan teknologi dan tuntutan jaman. Untuk mendukung hal tersebut maka lahirlah regulasi yang disebut sertifikasi guru. Selanjutnya keberadaan sekolah dan guru yang kompeten dan profesional atau guru yang sudah bersertifikasi diupayakan dapat merata disetiap wilayah.

Secara geografis distribusi atau persebaran sekolah yang tidak merata akan berkontribusi kurang baik terhadap kualitas pendidikan penduduk di suatu wilayah. Perbandingan jumlah guru yang bersertifikasi dan yang belum bersertifikasi juga turut memberikan peran dalam menunjang kualitas pembelajaran di sekolah. Mengingat sertifikasi guru merupakan proses uji kompetensi bagi calon atau guru dan selanjutnya diperoleh pengakuan dan atau meningkatkan kompetensi sesuai profesi yang dipilihnya. Sertifikasi juga merupakan pengakuan atau pemberian predikat pendidik yang kompeten dan professional bagi guru yang telah tersertifikasi tersebut.

1. Dalam rangka mengkaji serta menganalisis distribusi atau persebaran
Sekolah Dasar di setiap wilayah salah satunya dengan menggunakan peta digital berbasis SIG. Peta merupakan data informasi yang sangat penting dengan informasi yang terkandung di dalamnya, yang disesuaikan dengan kebutuhan informasi yang diharapkan. Dalam Perencanaan Daerah (Regional Planning) peta untuk: (1). Memberikan informasi pokok dari aspek keruangan tentang karakter dari satu daerah. (2) Sebagai alat analisis dalam mendapatkan suatu kesimpulan. (3) Sebagai alat untuk menjelaskan penemuan-penemuan penelitian yang dilakukan. (4) Sebagai alat untuk menjelaskan rencana-rencana yang diajukan. Peta juga membantu dalam petunjuk dan memberikan gambaran tentang daerah tertentu, memasukkan data dari lapangan dan pengolahan hasil penelitian.

Banyak penelitian yang memberikan informasi sebagai dasar dalam pengambilan kebijakan yang dilakukan, dan penelitian ini mengacu pada penelitian sebelumnya yang pernah dilakukan mengenai Pemetaan Sertifikasi Guru Sekolah Dasar Di Kecamatan Kembaran Kabupaten Banyumas oleh Bramasta (2014) merupakan contoh pemanfaatan teknologi sistem informasi geografis yang muaranya pada rekomendasi pemerintah dalam memanfaatkan teknologi geospasial pada berbagai kegiatan perencanaan dan informasi.

Sebagai salah satu wilayah administratif Kecamatan Kutasari Kabupaten Purbalingga informasi Distribusi Sekolah Dasar serta perbandingan guru yang sudah bersertifikasi dan yang belum bersertifikasi belum tersampaikan ke seluruh lapisan masyarakat. Di sisi lain hal tersebut berpengaruh terhadap kualitas pendidikan dan pembelajaran di 
sekolah. Sementara masyarakat membutuhkan informasi tersebut untuk dapat meentukan pilihan dalam memenuhi kebutuhan akan pendidikannya.

\section{METODOLOGI}

Tujuan dalam penelitian ini untuk mengetahui persebaran sekolah dasar dan perbandingan sertifikasi guru sekolah dasar. Sehingga diketahui merata dan tidaknya distribusi atau persebaran Sekolah Dasar tersebut serta perbandingan jumlah guru yang sudah bersertifikasi dan yang belum bersertifikasi di setiap Sekolah Dasar.

Penelitian ini merupakan penelitian deskriptif kualitatif dengan pendekatan keruangan yang merupakan salah satu pendekatan dalam geografi. Penelitian ini akan mengungkap fenomena yang terjadi mengenai persebaran Sekolah Dasar dan perbandingan jumlah sertifikasi guru Sekolah Dasar. Subyek dalam penelitian ini adalah Sekolah Dasar di Kecamatan Kutasari Kabupaten Purbalingga. Sumber data adalah data primer (titik lokasi Sekolah Dasar, studi dokumentasi) dan sekunder (peta administrasi, data sertifikasi guru Sekolah Dasar, data monografi kecamatan). Teknik pengumpulan data observasi dan SIG (Sistem Informasi Geografis) dengan software Arc Gis 10.1.

Analisis yang digunakan adalah analisis interaktif. Teknik ini berguna untuk mendapatkan jawaban atas masalah-masalah yang ditemukan kemudian menghubungkan dengan teoriteori yang melandasi. Model teknik analisis ini dimulai dari tahap pengumpulan data, analisis data dengan SIG, reduksi data, sajian data dan penarikan simpulan atau verifikasi.

Sesudah pengumpulan data selesai pada setiap unitnya, analisis data dilakukan bersamaan dengan proses pengumpulan data. Proses analisis dengan model interaktif sebagai berikut :

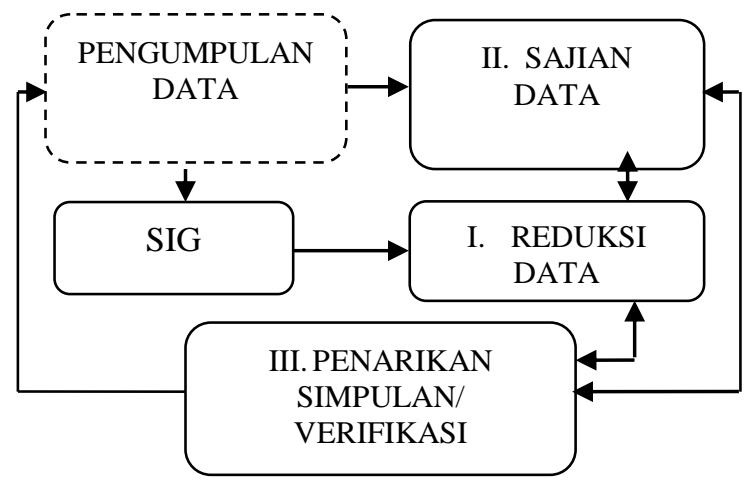

\section{Gambar 1. Model Analisis Interaktif dengan Sedikit Perubahan Sumber : Sutopo (1996 : 87)}

Untuk menganalisis perbandingan jumlah guru Sekolah Dasar yang sudah bersertifikasi dan guru yang belum bersertifikasi menggunakan deskriptif persentase.

Metode analisis data dalam penelitian ini, menggunakan analisis tetangga terdekat (nearest neighbour analysis) untuk menjelaskan persebaran atau distribusi Sekolah Dasar di Kecamatan Kutasari Kabupaten Purbalingga. Lebih jelasnya jenis analisis data yang digunakan dalam penelitian ini, dapat dijelaskan sebagai berikut :

Analisis persebaran atau distribusi Sekolah Dasar, dalam penelitian ini mencoba mengaitkan persebaran atau distribusi Sekolah Dasar di Kecamatan Kembaran Kabupaten Banyumas dengan analisis tetangga terdekat (nearest neighbour analysis) menggunakan aplikasi SIG dengan software Arcgis 10.1. Analisis ini digunakan untuk menganalisis persebaran atau distribusi Sekolah Dasar di Kecmatan Kutasari Kabupaten Purbalingga, apakah mengikuti pola random, mengelompok atau seragam, yang ditunjukkan dari besarnya nilai T. Hasil dari analisis ini, bisa memberikan gambaran terhadap kecenderungan mengapa menunjukkan kecenderungan 
pada suatu pola tertentu, dikaitkan dengan analisis faktor yang mempengaruhinya.

Nilai T/indeks penyebaran tetangga terdekat sendiri diperoleh melalui formula :

$$
\mathrm{T}=\frac{j_{u}}{j_{h}}
$$

Dimana :

$\mathrm{T}$ : indeks penyebaran tetangga terdekat

$j_{u} \quad: \quad$ jarak rata-rata yang diukur antara satu titik dengan titik tetangganya yang terdekat

$j_{h} \quad: \quad$ jarak rata-rata yang diperoleh andaikata semua titik mempunyai pola random $=\frac{1}{2 \sqrt{p}}$

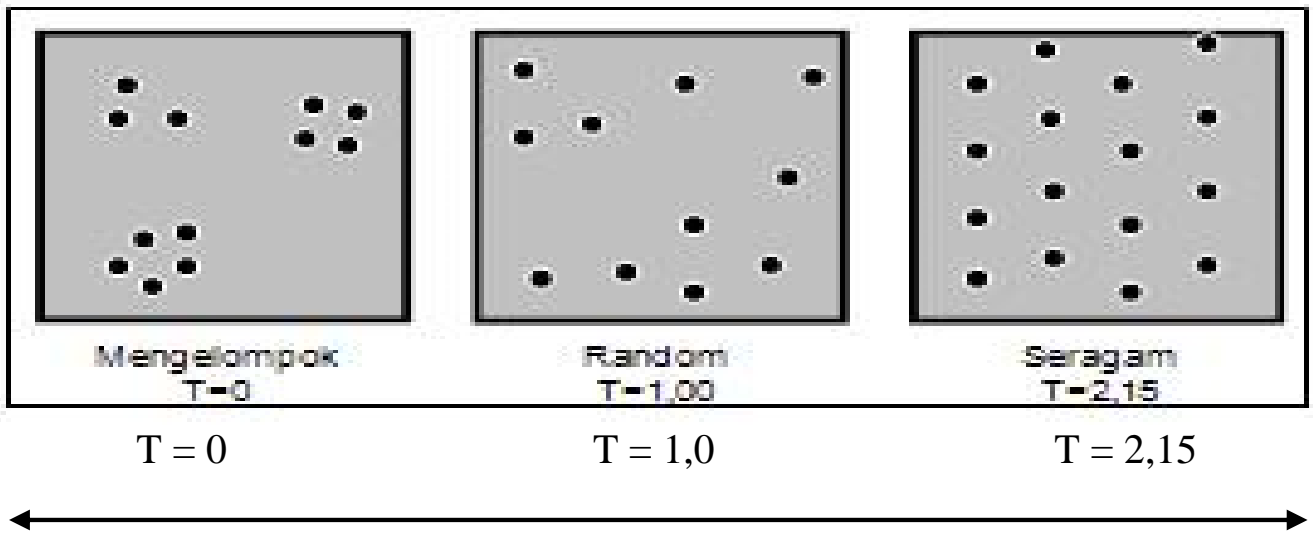

P : kepadatan titik dalam tiap

kilometer per segi yaitu jumlah titik (N) dibagi luas wilayah (A)

Dari nilai $\mathrm{T}$, selanjutnya diinterpretasikan dengan Continum Nearest Neighbour Analysis, sebagai berikut : 


\section{SSH Jurnal SAIS SOSIAL dan HUMANIORA}

Kecamatan Kutasari merupakan salah satu Kecamatan di bagian utara Kabupaten Purbalingga dengan luas wilayah 52,90 $\mathrm{Km}^{2}$ berada pada ketinggian $375 \mathrm{~m}$ dpl. Kecamatan Kutasari terdiri dari 14 Desa yaitu Desa Karanglewas, Desa Munjul, Desa Sumingkir, Desa Meri, Desa Kutasari, Desa Karangklesem, Desa Karangreja, Desa Karangaren, Desa Limbangan, Desa Cendana, Desa Candiwulan, Desa Karangcegak, Desa Candinata, Desa Karangjengkol.

Secara geografis Kecamatan Kutasari merupakan daerah pegunungan yang memiliki jarak cukup jauh dari pusat pemerintahan Kabupaten. Sehingga penduduknya untuk mendapatkan akses pendidikan yang memadai tidak memungkinkan melakukan perjalanan byang cukup jauh ke pusat kota yang memakan waktu dan biaya. Terdapat 26 Sekolah Dasar di Kecamatan Kutasari. (BPS Purbalingga, 2015)

Berdasarkan data BPS Kecamatan Kutasari Kabupaten Purbalingga tahun 2015, Kecamatan Kembaran mempunyai batas wilayah sebagai berikut :

1) Sebelah utara : Kecamatan Bojongsari

2) Sebelah selatan : Kecamatan Padamara

3) Sebelah barat : Kabupaten Banyumas

4) Sebelah timur : Kecamatan Bojongsari

Batas-batas wilayah Kecamatan Kutasari dapat dilihat pada Peta administrasi Kecamatan Kutasari berikut : 


\section{Jurnal}

JSSH SAINS SOSIAL dan HUMANIORA

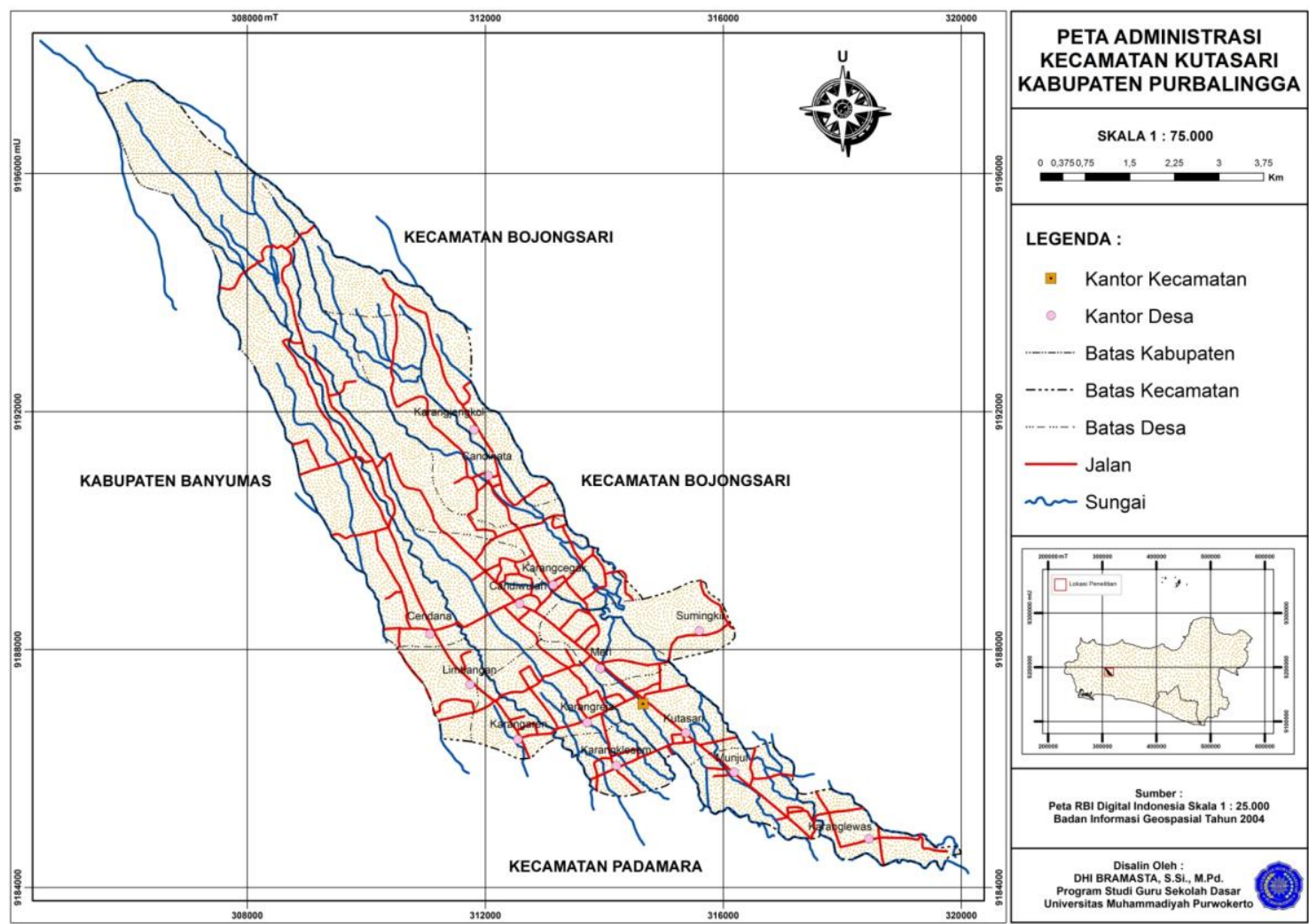

Luas wilayah Kecamatan Kutasari 38,08 $\mathrm{Km}^{2}$ terdiri dari 14 desa yaitu Desa Karanglewas, Desa Munjul, Desa Sumingkir, Desa Meri, Desa Kutasari, Desa Karangklesem, Desa Karangreja, Desa Karangaren, Desa Limbangan, Desa Cendana, Desa Candiwulan, Desa Karangcegak, Desa Candinata, Desa Karangjengkol (BPS Purbalingga, 2015). Luas wilayah tiap Desa disajikan pada Tabel 1 di bawah ini :

Tabel 1. Luas Wilayah Tiap Desa Kecamatan Kutasari Tahun 2015

\begin{tabular}{|c|l|c|c|}
\hline No & Kelurahan & Luas $\left(\mathbf{K m}^{\mathbf{2}}\right)$ & $\mathbf{\%}$ \\
\hline 1 & Karanglewas & 1 & 2,63 \\
\hline 2 & Munjul & 1,43 & 3.76 \\
\hline 3 & Karangklesem & 1,31 & 3.44 \\
\hline 4 & Kutasari & 2,01 & 5.28 \\
\hline 5 & Sumingkir & 1,86 & 4.88 \\
\hline 6 & Meri & 1,68 & 4.41 \\
\hline 7 & Karangreja & 2,72 & 7.14 \\
\hline 8 & Karangaren & 0,73 & 1.92 \\
\hline 9 & Limbangan & 2,07 & 5.44 \\
\hline
\end{tabular}

\begin{tabular}{|c|l|c|c|}
\hline 10 & Cendana & 5,59 & 14.68 \\
\hline 11 & Candiwulan & 3,36 & 8.82 \\
\hline 12 & Karangcegak & 4,14 & 10.87 \\
\hline 13 & Candinata & 6,60 & 17.33 \\
\hline 14 & Karangjengkol & 3,58 & 9.40 \\
\hline & Jumlah & $\mathbf{3 8 , 0 8}$ & $\mathbf{1 0 0}$ \\
\hline
\end{tabular}

Sumber : Kecamatan Kutasari dalam Angka 2015

Dari Tabel 1 di atas dapat diketahui bahwa Desa yang memiliki luas wilayah paling besar adalah Desa Candinata dengan luas $6,60 \mathrm{Km}^{2}$ atau 17,33 \%. Kemudian Desa yang memiliki luas wilayah paling kecil adalah Desa Karangaren dengan luas $0,73 \mathrm{Km}^{2}$ atau $1,19 \%$ dari luas wilayah Kecamatan Kutasari.

\section{B. Jumlah Penduduk Menurut Mata Pencaharian}

Mata pencaharian penduduk Kecamatan Kutasari bervariasi, disajikan pada Tabel 2 berikut : 
Tabel 2. Jumlah Penduduk Menurut Mata Pencaharian Tiap Desa di Kecamatan Kutasari

Kabupaten Purbalingga Tahun 2015

\begin{tabular}{|c|c|c|c|c|c|c|c|c|c|c|c|c|}
\hline No & Kelurahan & Petani & $\begin{array}{c}\text { Buruh } \\
\text { Tani }\end{array}$ & $\begin{array}{c}\text { Buruh } \\
\text { Industri }\end{array}$ & Bangunan & Pengusaha & Pedagang & Angkutan & PNS & ABRI & Pensiunan & Jumlah \\
\hline (1) & (2) & (3) & (4) & (5) & (6) & (7) & (8) & (9) & (10) & (11) & & (12) \\
\hline 1 & $\begin{array}{l}\text { Kranglewa } \\
\text { s }\end{array}$ & 120 & 458 & 343 & 202 & 27 & 142 & 18 & 54 & 3 & 68 & 1.435 \\
\hline 2 & Munjul & 217 & 312 & 236 & 228 & 34 & 284 & 7 & 78 & 6 & 51 & 2.034 \\
\hline 3 & $\begin{array}{l}\text { Karanglese } \\
\text { m }\end{array}$ & 324 & 766 & 496 & 181 & 19 & 142 & 6 & 56 & 6 & 22 & 2.018 \\
\hline 4 & Kutasari & 299 & 1.125 & 812 & 389 & 174 & 614 & 34 & 71 & 7 & 40 & 3.565 \\
\hline 5 & Sumingkir & 290 & 1.986 & 643 & 183 & 98 & 118 & 31 & 92 & 6 & 65 & 3.512 \\
\hline 6 & Meri & 252 & 987 & 432 & 222 & 251 & 138 & 22 & 64 & 4 & 36 & 2.408 \\
\hline 7 & Karangreja & 965 & 1.254 & 714 & 345 & 56 & 216 & 98 & 46 & 9 & 48 & 3.751 \\
\hline 8 & $\begin{array}{l}\text { Karangare } \\
\mathrm{n}\end{array}$ & 138 & 125 & 262 & 56 & 16 & 134 & 8 & 7 & 4 & 12 & 762 \\
\hline 9 & Limbangan & 471 & 789 & 345 & 197 & 27 & 132 & 22 & 28 & 0 & 23 & 2.034 \\
\hline 10 & Cendana & 425 & 1.543 & 254 & 181 & 18 & 89 & 16 & 6 & 0 & 3 & 2.535 \\
\hline 11 & $\begin{array}{l}\text { Candiwula } \\
\mathrm{n}\end{array}$ & 485 & 655 & 547 & 428 & 87 & 243 & 64 & 33 & 4 & 24 & 2.570 \\
\hline 12 & $\begin{array}{l}\text { Karangceg } \\
\text { ak }\end{array}$ & 345 & 2.876 & 399 & 215 & 35 & 156 & 28 & 23 & 6 & 18 & 4.101 \\
\hline 13 & Candinata & 493 & 1.134 & 914 & 431 & 42 & 235 & 48 & 18 & 0 & 24 & 3.339 \\
\hline 14 & $\begin{array}{l}\text { Karangjen } \\
\text { gkol }\end{array}$ & 1.122 & 412 & 102 & 78 & 23 & 112 & 9 & 8 & 0 & 5 & 1.871 \\
\hline \multicolumn{2}{|c|}{ Jumlah } & 5.946 & $\begin{array}{c}14.42 \\
2\end{array}$ & 6.499 & 3.336 & 907 & 2.755 & 411 & 584 & 55 & 439 & $\begin{array}{c}35.35 \\
4\end{array}$ \\
\hline
\end{tabular}

Sumber : Statistik Kecamatan Kutasari Tahun 2015

Tabel tersebut menunjukkan bahwa mata pencaharian penduduk Kecamatan Kutasari yang tertinggi pada sektor buruh, baik itu buruh tani ataupun buruh industri yaitu 14.422 orang untuk buruh tani dan 6.499 orang untuk buruh industri. Hal ini sangat rasional mengingat Kecamatan Kutasari dengan luas total $38,08 \mathrm{Km}^{2}$ tersebut, $59 \%$ dari luas wilayahnya berfungsi sebagai lahan pertanian dengan luasan mencapai mencapai 22,58 $\mathrm{Km}^{2}$. Lahan pertanian tersebut terdiri dari $9,12 \mathrm{Km}^{2}$ sawah berpengairan teknis dan non teknis, 1,24 $\mathrm{Km}^{2}$ tidak beririgasi. Kemudian lahan pertanian non sawah berupa tegalan dan kolam seluas 12,21 $\mathrm{Km}^{2}$ Dari tahun ke tahun terdapat kecenderungan berkurangnya lahan pertanian terutama sawah karena seperti umumnya masalah kependudukan di tanah air disebabkan oleh pertumbuhan penduduk dan perkembangan perekonomian maka membutuhkan lahan untuk hunian atau tempat tinggal serta aktivitas ekonomi. Sedangkan buruh industri memiliki jumlah yang besar pula dikarenakan berkembangnya industri padat karya di
Kecamatan Kutasari terutama industri rambut yang sebagian besar PMA dari Korea banyak sekali menyerap tenaga kerja. Dalam proses produksinya pengerjaannya tidak hanya di dalam pabrik atau perusahaan tetapi juga dikerjakan di masing masing rumah para pekerjanya. Hal ini banyak ditemukan di semua desa di Kecamatan Kutasari. Jenis mata pencaharian yang mempunyai jumlah terendah pada sektor ABRI yaitu 55 orang, dikarenakan ABRI merupakan alat negara untuk menjaga keamanan dalam masyarakat dan jumlah yang ditempatkan oleh pemerintah sesuai dengan kebutuhan dan tingkat kriminalitas yang terjadi pada masyarakat.

\section{Penggunaan Lahan}

Penggunaan lahan Kecamatan Kutasari menurut desa disajikan pada Tabel 3 berikut :

Tabel 3. Luas Wilayah Menurut Desa dan Penggunaannya kecamatan Kutasari Kabupaten Purbalingga Tahun 2014 (Ha)

\begin{tabular}{|c|c|c|c|c|}
\hline No & Desa & $\begin{array}{l}\text { Tanah } \\
\text { Basah }\end{array}$ & $\begin{array}{l}\text { Tanah } \\
\text { Kering }\end{array}$ & Jumlah \\
\hline
\end{tabular}




\begin{tabular}{|c|l|c|c|c|}
\hline 1 & Karanglewas & 76,68 & 23,34 & 100,03 \\
\hline 2 & Munjul & 99,81 & 42,74 & 142,55 \\
\hline 3 & Karangklesem & 99,63 & 31,34 & 130,97 \\
\hline 4 & Kutasari & 111,66 & 89,44 & 201,10 \\
\hline 5 & Sumingkir & 107,40 & 78,94 & 186,34 \\
\hline 6 & Meri & 86,22 & 82,28 & 168,50 \\
\hline 7 & Karangreja & 120,65 & 151,67 & 272,32 \\
\hline 8 & Karangaren & 49,56 & 23,04 & 72,60 \\
\hline 9 & Limbangan & 53,92 & 152,75 & 206,67 \\
\hline 10 & Cendana & 0,00 & 559,00 & 559,00 \\
\hline 11 & Candiwulan & 55,86 & 280,39 & 336,25 \\
\hline 12 & Karangcegak & 69,26 & 344,76 & 414,02 \\
\hline 13 & Candinata & 45,86 & 613,94 & 659,80 \\
\hline 14 & Karangjengkol & 19,92 & 338,02 & 357,94 \\
\hline \multicolumn{2}{|l|}{ Jumlah } & $\mathbf{9 9 6 . 4 3}$ & $\mathbf{2 , 8 1 1 , 6 5}$ & $\mathbf{3 , 8 0 8 , 0 9}$ \\
\hline
\end{tabular}

Sumber : Kecamatan Kutasari dalam Angka

\section{5}

Tabel di atas menunjukkan perbandingan penggunaan lahan antara tanah basah dan kering di Kecamatan
Kutasari Kabupaten Purbalingga lebih didominasi oleh tanah kering. Hal ini dikarenakan sebagian wilayah kecamatan Kutasari merupakan hutan negara dan tanah basah dari tahun ke tahun mengalami penurunan karena laju pertumbuhan penduduk di Kecamatan Kutasari dari tahun ke tahun mengalami peningkatan, sehingga kebutuhan ruang juga mengalami peningkatan seiring meningkatnya laju pertumbuhan penduduk tersebut untuk memenuhi kebutuhan tempat tinggal penduduk.

Penggunaan lahan Kecamatan Kutasari dapat dilihat pada Peta 2 berikut

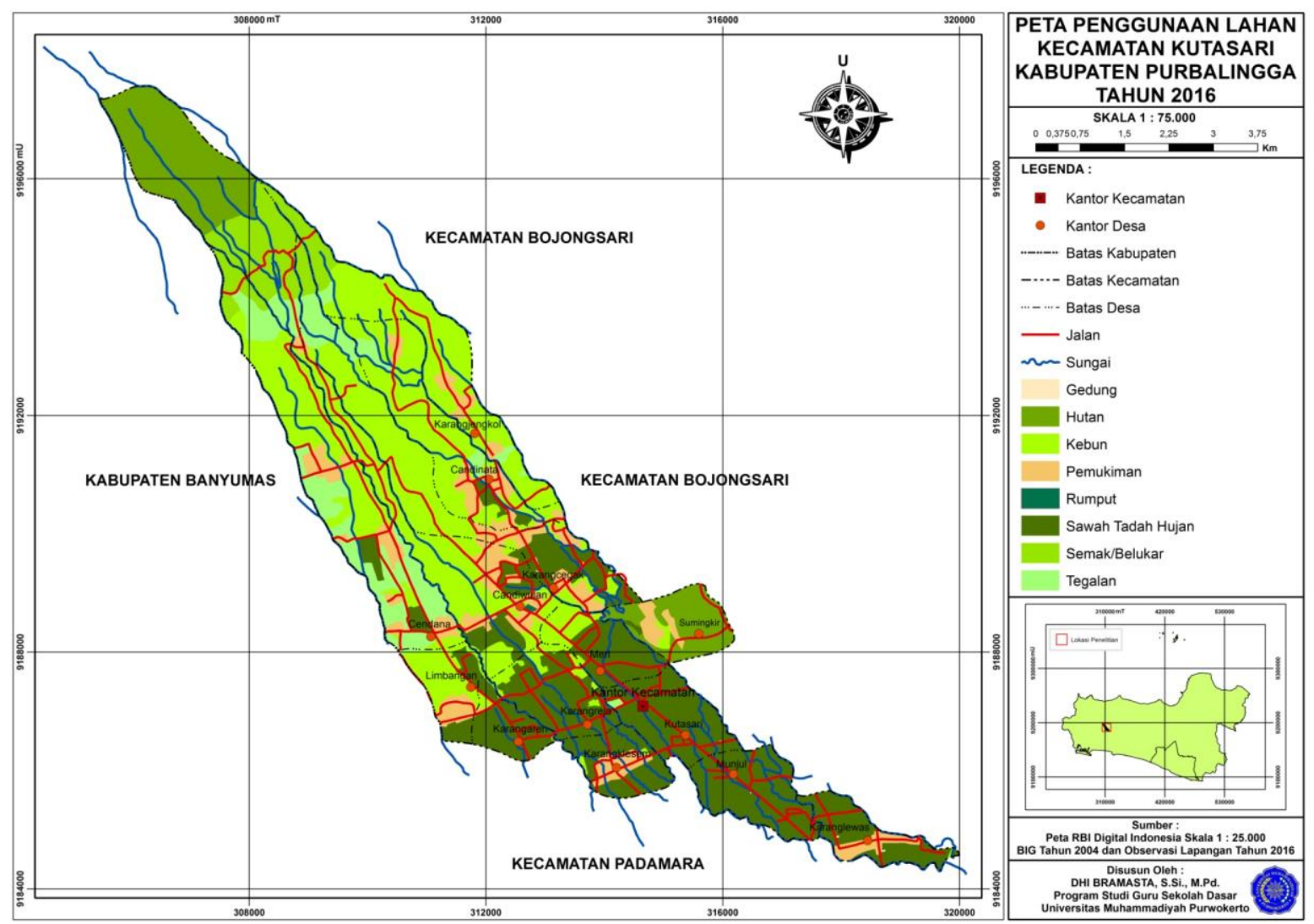

\section{Komposisi Penduduk Menurut Pendidikan}

Adapun komposisi penduduk menurut pendidikan Kecamatan Kutasari Kabupaten Purbalingga disajikan pada Tabel 4 berikut ini
Tabel 4. Penduduk Kecamatan Kutasari Menurut Pendidikan Tahun 2013/2014

\begin{tabular}{|c|l|c|c|c|}
\hline No & \multicolumn{1}{|c|}{ Desa } & $\begin{array}{c}\text { Tamat } \\
\text { SD }\end{array}$ & $\begin{array}{c}\text { Tamat } \\
\text { SLTP }\end{array}$ & $\begin{array}{c}\text { Tamat } \\
\text { SLTA }\end{array}$ \\
\hline 1 & Karanglewas & 42 & - & - \\
\hline 2 & Munjul & 50 & 206 & - \\
\hline 3 & Karangklesem & 41 & 70 & - \\
\hline 4 & Kutasari & 95 & - & - \\
\hline 5 & Sumingkir & 77 & - & - \\
\hline
\end{tabular}




\begin{tabular}{|c|l|c|c|c|}
\hline 6 & Meri & 41 & 205 & 214 \\
\hline 7 & Karangreja & 93 & 91 & - \\
\hline 8 & Karangaren & - & - & - \\
\hline 9 & Limbangan & 64 & - & - \\
\hline 10 & Cendana & 13 & 93 & - \\
\hline 11 & Candiwulan & 74 & - & - \\
\hline 12 & Karangcegak & 120 & - & - \\
\hline 13 & Candinata & 112 & - & - \\
\hline 14 & Karangjengkol & 64 & 70 & - \\
\hline \multicolumn{2}{|c|}{ Jumlah } & $\mathbf{8 8 6}$ & $\mathbf{7 3 5}$ & $\mathbf{2 1 4}$ \\
\hline
\end{tabular}

Sumber : Kecamatan Kutasari dalam Angka 2015

Memperhatikan tabel di atas, dapat diketahui bahwa Desa Meri potensi untuk penduduk dengan tamatan SMA yang cukup banyak yaitu 214 orang. Rata-rata tingkat pendidikan di wilayah Kecamatan Kutasari adalah tamatan SD, Desa Karangcegak mempunyai tamatan SD yang paling banyak yaitu 120 orang atau sekitar 13,54 \%. Disusul Desa Candinata sebanyak 112 orang atau sekitar 12,64\% dan ketiga Desa Kutasari sebanyak 95 orang atau sekitar 10,72\%.

\section{E. Kondisi Sosial Ekonomi Penduduk}

Kecamatan Kutasari merupakan salah satu Kecamatan di Kabupaten Purbalingga. Di Kabupaten Purbalingga perkembangan industrinya cukupm signifikan, salah satunya adalah Industri bulu mata palsu. Industri ini merupakan salah satu industri yang berkembang pesat di Purbalingga. Sejak tahun 1980 hingga sekarang terdapat sekitar 28 perusahaan bulu mata dan rambut palsu dengan jumlah karyawan mencapa 15.698 orang. Dari sekian banyak perusahaan, terdapat beberapa perusahaan yang membuka cabang di desa-desa atau yang kerap disebut plasma. Mayoritas buruh yang bekerja di plasma adalah perempuan dan sebagian besar sudah berkeluarga.

Kecamatan Kutasari tidak luput dari pengaruh perkembangan industri tersebut, hal ini ditunjukkan dengan terdapatnya cabang atau plasma yang ada di Kecamatan Kutasari ini. Sehingga relevan jika penduduk Kecamatan Kutasari mayoritas mata pencahariannya pada sektor buruh.

\section{F. Persebaran Sekolah Dasar}

Persebaran Sekolah Dasar di Kecamatan Kutasari merata di seluruh wilayah, persebaran Sekolah Dasar daerah penelitian dapat dilihat pada Tabel 5 berikut :

Tabel 5. Persebaran Sekolah Dasar Kecamatan Kutasari Tahun 2016

\begin{tabular}{|c|c|c|c|c|c|}
\hline \multirow{2}{*}{ No } & \multirow{2}{*}{ Nama Sekolah } & \multirow{2}{*}{ Lokasi } & \multirow{2}{*}{ Desa } & \multicolumn{2}{|c|}{ Koordinat } \\
\hline & & & & $\mathbf{X}(\mathbf{m} \mathbf{T})$ & $\mathbf{Y}(\mathbf{m U})$ \\
\hline 1 & SD N 1 Cendana & Jl. Raya Cendana & Cendana & 311098 & 9188379 \\
\hline 2 & SD N 2 Cendana & Jl. Raya Kebogoan Cendana & Cendana & 309603 & 9191163 \\
\hline 3 & SD N 1 Limbangan & Jl. Raya Limbangan RT 6 RW 3 & Limbangan & 311593 & 9187741 \\
\hline 4 & SD N 1 Karangaren & Jl. Raya Krasen & Karangaren & 312659 & 9186427 \\
\hline 5 & SD N 1 Karangklesem & Desa Karanglesem & Karangaren & 313941 & 9185898 \\
\hline 6 & SD N 1 Munjul & Desa Munjul & Munjul & 316502 & 9185757 \\
\hline 7 & SD N 2 Munjul & J1. Raya Tobong & Munjul & 316087 & 9186043 \\
\hline 8 & SD N 1 Karanglewas & J1. Raya Karanglewas & Karanglewas & 318547 & 9184853 \\
\hline 9 & SD N 1 Kutasari & Jl. Raya Tobong & Kutasari & 314805 & 9187040 \\
\hline 10 & SD N 2 Kutasari & Jl. Raya Tobong No. 71 A & Kutasari & 315438 & 9186545 \\
\hline
\end{tabular}




\begin{tabular}{|l|l|l|l|l|l|}
11 & SD N 1 Karangreja & Desa Karangreja & Karangreja & 313746 & 9186545 \\
\hline 12 & SD N 2 Karangreja & Desa Karangreja & Karangreja & 313318 & 9187664 \\
\hline 13 & SD N 1 Meri & Jl. Raya Tobong No. 41 & Meri & 313906 & 9187775 \\
\hline 14 & SD N 1 Sumingkir & Jl. Raya Sumingkir & Sumingkir & 315458 & 9188001 \\
\hline 15 & SD N 2 Sumingkir & Jl. Lemah Meteng RT 11 RW 5 & Sumingkir & 315925 & 9188586 \\
\hline 16 & SD N 3 Sumingkir & Jl. Dawuhan & Sumingkir & 314787 & 9188376 \\
\hline 17 & SD N 1 Candiwulan & Jl. Raya Tobong No. 2 RT 10 RW 5 & Candiwulan & 312756 & 9188666 \\
\hline 18 & SD N 2 Candiwulan & Desa Candiwulan & Candiwulan & 310254 & 9191011 \\
\hline 19 & SD N 1 Karangcegak & Jl. Raya Karangcegak RT 4 RW 2 & Karangcegak & 313626 & 9189534 \\
\hline 20 & SD N 2 Karangcegak & Jl. Raya Karangcegak & Karangcegak & 312918 & 9189510 \\
\hline 21 & SD N 1 Candinata & Jl. Raya Candinata RT 4 RW 2 & Candinata & 312344 & 9190411 \\
\hline 22 & SD N 2 Candinata & Jl. Limpakpring & Candinata & 310402 & 9192775 \\
\hline 23 & SD N 3 Candinata & Jl. Karangkedawung & Candinata & 312014 & 9190764 \\
\hline 24 & SD N 1 Karangjengkol & Jl. Raya Karangjengkol & Karangjengkol & 311827 & 9191791 \\
\hline 25 & SD N 2 Karangjengkol & Jl. Raya Karangjengkol & Karangjengkol & 311304 & 9192756 \\
\hline 26 & SD N 3 Karangjengkol & Jl. Limpak Tepus RT 12 RW 4 & Karangjengkol & 310461 & 9193959 \\
\hline & & & & \\
\hline
\end{tabular}

Sumber : UPTD Kecamatan Kutasari dan Observasi Lapangan Tahun 2016

Terdapat 26 Sekolah Dasar di Kecamatan Kutasari Kabupaten Purbalingga. Persebaran tersebut merata di setiap Desa. Desa Cendana terdapat 2 Sekolah Dasar, Desa Limbangan, Desa Karangaren, Desa Karangklesem, Desa Karanglewas, Desa Meri masing-masing terdapat 1 Sekolah Dasar, Desa Munjul terdapat 2 Sekolah Dasar, Desa Kutasari terdapat 2 Sekolah Dasar, Desa Karangreja terdapat 2 Sekolah Dasar, Desa Sumingkir terdapat 3 Sekolah Dasar, Desa Candiwulan terdapat 2 Sekolah Dasar, Desa Karangcegak terdapat 2 Sekolah Dasar, Desa Candinata terdapat 3 Sekolah Dasar, Desa Karangjengkol terdapat 3 Sekolah Dasar. Artinya 9 Desa terdapat lebih dari 1 Sekolah Dasar, untuk Desa yang lain hanya terdapat 1 Sekolah Dasar. Hal ini menujukkan bahwasannya Kecamatan Kutasari Kabupaten Purbalingga dalam hal kebutuhan pendidikan khususnya pendidikan dasar sudah mencukupi, ditunjukkan terdapat minimal 1 Sekolah Dasar di setiap Desa. Persebaran Sekolah Dasar Kecamatan Kutasari dapat dilihat pada Peta 4.3 berikut ini :

Untuk megetahui persebaran sekolah dasar dilakukan plotting titik lokasi dengan menggunakan teknologi survey GPS (Global Positioning System) seperti terlihat pada gambar 1 berkut :
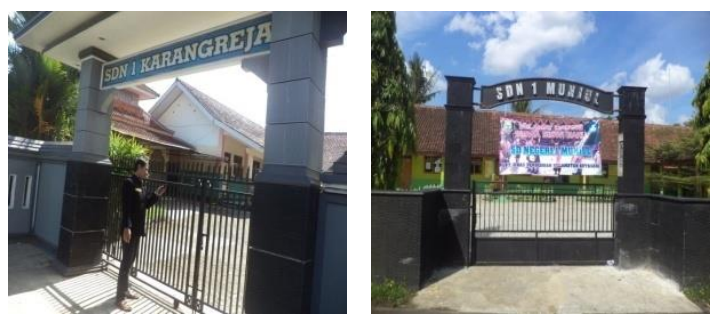

Gambar 1. Plotting Titik Koordinat SD Negeri Karangreja dan SD Negeri 1 Munjul Tampak Depan menggunakan GPS (Global Positioning System) 


\section{Jurnal \\ JSSH SAINS SOSIAL dan HUMANIORA}

Data titik lokasi atau koordinat Sekolah

aplikasi SIG (Sistem Informasi Geografis) dengan perangkat lunak Arc Gis 10.1 dan akan diketahui persebarannya. Persebaran Sekolah Dasar Kecamatan Kutasari dapat dilihat pada Peta 3 berikut ini :

Dasar kemudian di upload ke dalam

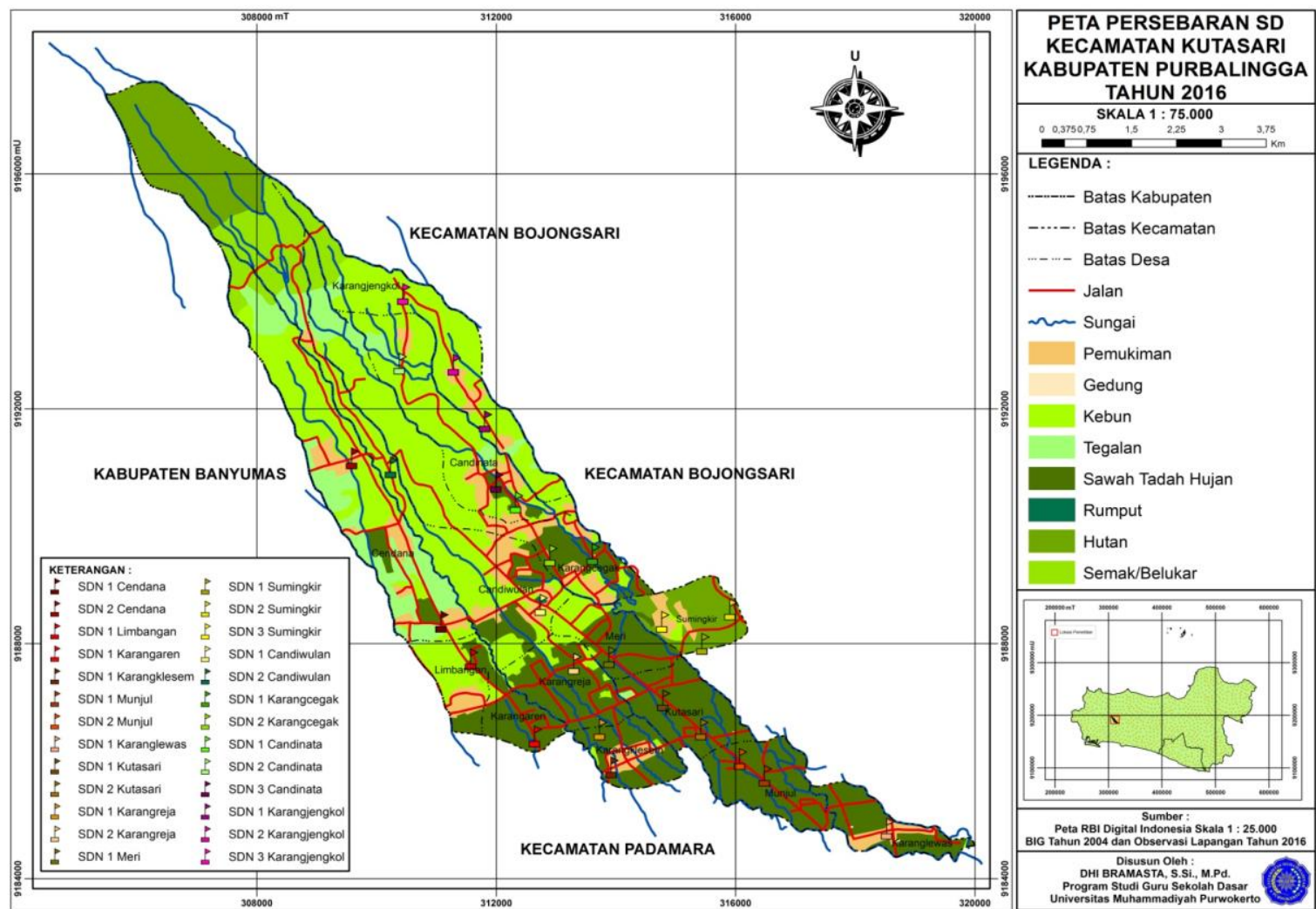

Sesuai dengan hasil analisis tetangga terdekat (nearest neighbour analysis) menggunakan aplikasi SIG, persebaran dan pola keruangan Sekolah Dasar Kecamatan Kutasari disajikan pada Gambar 2 berikut :

Average Nearest Neighbor Summary

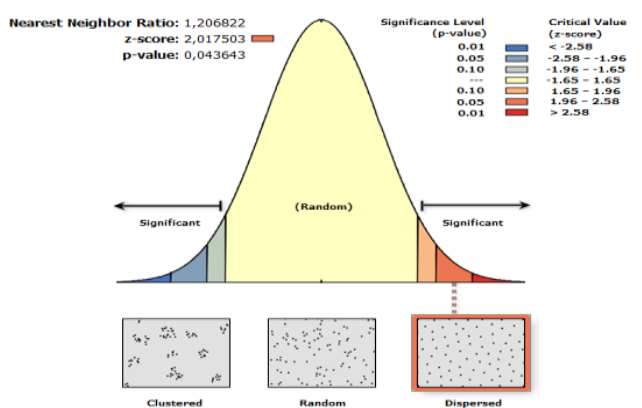

Given the $z$-score of 2.02 , there is a less than $5 \%$ likelihood that this dispersed pattern could be thesult of random chance.

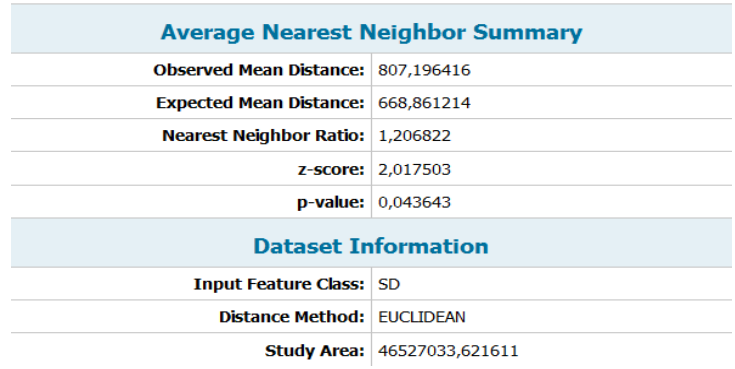

Gambar 2. Hasil Analisis Tetangga Terdekat /Nearest Neighbour Analysis Sumber : Data Primer 2016

Persebaran Sekolah Dasar Kecamatan Kutasari adalah dispersed/seragam berpola mengikuti atau berdekatan dengan jalan raya. Hal ini disebabkan Kecamatan Kutasari merupakan daerah pegunungan, 
sehingga pembangunan sekolah secara hirarki ditujukan agar memberikan kemudahan penduduk untuk menjangkaunya.

\section{G. Perbandingan Sertifikasi Guru Sekolah Dasar}

Perbandingan jumlah guru yang bersertifikasi dan yang belum bersertifikasi Kecamatan Kutasari lebih banyak yang sudah bersertifikasi. Terdapat 4 orang guru atau 2,34\% guru Sekolah Dasar yang belum bersertifikasi, dan 167 orang guru atau 97,66 \% guru Sekolah Dasar yang sudah bersertifikasi dari jumlah keseluruhan guru 171 orang guru di Kecamatan Kutasari Kabupaten Purbalingga.

Dapat diketahui perbandingan guru Sekolah Dasar yang sudah bersertifikasi dan yang belum bersertifikasi di Kecamatan Kutasari Kabupaten Purbalingga lebih banyak yang sudah bersertifikasi. Hal tersebut sebagai wujud dari kepedulian pemerintah daerah Kecamatan Kembaran untuk mensejahterakan guru dan meningkatkan mutu guru.

\section{PENUTUP}

\section{A. Kesimpulan}

1. Persebaran Sekolah Dasar Kecamatan Kutasari adalah dispersed/seragam merata di seluruh wilayah Kecamatan Kutasari, tersebar mengikuti jalan raya. Hal ini ditujukan agar Sekolah Dasar di daerah tersebut mudah untuk dijangkau penduduk. Terdapat 26 Sekolah Dasar di wilayah tersebut. Desa Karangjengkol, Desa Candinata dan Desa Sumingkir yang masing-masing daerah tersebut terdapat 3 Sekolah Dasar yang merupakan Desa yang memiliki jumlah Sekolah Dasar terbanyak. Hal ini dikarenakan ketiga Desa tersebut merupakan daerah yang memliki jarak relatif paling jauh dari pusat Kota Kabupaten, Desa Candinata memiliki jarak 12,30 Km, Desa Sumingkir memiliki jarak $10 \mathrm{Km}$ dan Desa Karangjengkol memiliki jarak 10,10 Km dari pusat Kota Kabupaten.

2. Perbandingan jumlah guru yang bersertifikasi dan yang belum bersertifikasi Kecamatan Kutasari lebih banyak yang sudah bersertifikasi. Terdapat 4 orang guru atau 2,34 \% guru Sekolah Dasar yang belum bersertifikasi, dan 167 orang guru atau 97,66 \% guru Sekolah Dasar yang sudah bersertifikasi dari jumlah keseluruhan guru 171 orang guru di Kecamatan Kutasari Kabupaten Purbalingga.

\section{B. Saran}

1. Perbaikan akses menuju lokasi sekolah perlu diadakan perbaikan, karena sebagian banyak yang rusak dan kurang memadai. Selain hal tersebut Kecamatan Kutasari merupakan daerah pegunungan dan terdapat akses jalan yang memiliki kemiringan yang curam dan kelokan yang tajam sehingga sangat membahayakan bagi penduduk yang akan melakukan perjalanan dalam memenuhi kebutuhan pendidikannya jika melewati jalan tersebut, sehingga perlu diperbaiki supaya berkurang tingkat kecuraman dan ketajaman kelokannya.

2. Pemerintah perlu lebih meningkatkan program sertifikasi guru Sekolah Dasar, agar semua guru dapat tersertifikasi serta benar-benar memperhatikan kopetensi dan kualitas guru tersebut. Sehingga seiring dengan meningkatnya kompetensi dan kualitas dan guru akan meningkat pula kualitas dan mutu pendidikan Sekolah Dasar di 


\section{Jurnal \\ ISSH SAINS SOSIAL dan HUMANIORA}

Kecamatan Kutasari Kabupaten Purbalingga.

[6] Sutopo, HB. 1996. Metodelogi Penelitian Kualitatif, Metode Penelitian untuk Ilmu

\section{DAFTAR PUSTAKA}

[1] Badan Pusat Statistik. 2015. Statistik Daerah Kecamatan Kutasari. Purbalingga.

[2] Bintarto, R dan Hadisumarno. 1982. Metode Analisa Geografi, Jakarta, LP3ES.

[3] Bramasta, Dhi, 2014. Pemetaan Sertifikasi Guru Sekolah Dasar Di Kecamatan Kembaran Kabupaten Banyumas Tahun 2014. Pendidikan Guru Sekolah Dasar Universitas Muhammadiyah Purwokerto : Surakarta.

[4] Mulyasa, E. 2005. Kurikulum Berbasis Kompetensi : Konsep, Karateristik, dan Impelemtasi Bandung : Remaja Rosda Karya.

[5] Notoatmojo Soekidjo, 2003.

Pengembangan Sumber Daya Manusia. Jakarta: Rineka Cipta.
Sosial dan Budaya. Surakarta : UNSA

Press.

[7] Unit Pendidikan Kecamatan. 2016. Data Sertifikasi Guru Sekolah Dasar Kecamatan Kutasari. Diknas Kabupaten Purbalingga. 